\title{
Smart specialisation in Sub-Saharan Africa: opportunities and challenges
}

\author{
Mafini Dosso ${ }^{1}$, Alexander Kleibrink ${ }^{2}$, Monika Matusiak ${ }^{3}$ \\ Mafini.dosso@ec.europa.euㄴ,Alexander.Kleibrink@ec.europa.eu², Monika.matusiak@ec.europa.eu³ \\ ${ }^{123}$ European Commission, Joint Research Centre, Seville, Spain
}

\begin{abstract}
This paper calls for a better integration of place-, evidence-based and inclusive dimensions in the implementation of the Science, Technology and Innovation (STI) strategic plans in sub-Saharan Africa. The study contrasts with and takes inspiration from the recent and ongoing international experiences in the elaboration of Innovation Strategies for Smart Specialisation. Pragmatic recommendations are drawn for more effective innovation-based local development strategies.
\end{abstract}

Keywords: STI policies, smart specialisation, industrial transformation, sub-Saharan Africa

\section{Introduction}

The 2030 Agenda for Sustainable Development ${ }^{1}$ underlines the need for countries, independently of their development stage, to Build resilient infrastructure, promote inclusive and sustainable industrialization and foster innovation (SDG 9). The African Union Agenda 2063 also refers to science, technology and innovation (STI) as multi-functional enablers for achieving continental development goals. In Africa, awareness of the role of innovation has only recently led to the elaboration of STI strategies at the continental ${ }^{2}$ level and in a few countries. Nevertheless, policy-makers will still need to translate this shift in narrative into effective implementation and monitoring mechanisms.

This short paper acknowledges and restates the broad challenges of existing STI plans and policies in sub-Saharan Africa and calls for a better integration of place-, evidence-based and inclusive components for effective innovation-based development strategies. In order to do so, it takes inspiration from the recent and ongoing European and international experiences in the elaboration of Research and Innovation Strategies for Smart Specialisation ${ }^{3}$ or RIS3 (Gianelle et al 2016, World Bank 2015). RIS3 are place-based transformation agendas, which aim at developing competitive advantages through matching research and innovation assets to local challenges and business needs and capabilities. The main aim here is to discuss the challenges and opportunities of such territorial or place-based approach in the sub-Saharan African context. A key driving research question is to study to what extent 'innovation' policies may support territorial development through the mobilization and effective use of local assets.

The remainder of the paper is organized as follows. Section 2 reviews the key bottlenecks of current 'innovation' policies or plans in sub-Saharan Africa. Section 3 introduces the smart specialisation approach and discusses the new perspectives it opens for local innovation policy making and implementation in sub-Saharan Africa. Section 4 concludes with pragmatic recommendations on the way forward to start a pilot project on smart specialisation in subSaharan African countries.

\footnotetext{
${ }^{1}$ http://www.un.org/sustainabledevelopment/sustainable-development-goals/

2 The recent shift in the policy thinking has been marked by the early Africa's S\&T Consolidated Plan of Action endorsed in 2006 (Khartoum Summit) and the adoption of the STI Strategy for Africa - 2024 (STISA-2024, $23^{\text {rd }}$ Ordinary session, 2014) (AUC, 2014). See also UNECA (2016) and the UNESCO's African STI Policy Initiative, http://www.unesco.org/new/en/natural-sciences/science-technology/stipolicy/africa/launch-of-the-african-science-technology-and-innovation-policy-initiative/

${ }_{3}^{3}$ EU's Smart specialisation platform http://s3platform.jrc.ec.europa.eu;
} 


\section{STI policy making and implementation in Sub-Saharan Africa: main bottlenecks}

With an average growth of $5 \%$, the first decade of the new millennium marked a period of sustained growth in sub-Saharan Africa. This rise was mainly driven by rising commodity prices combined with greater public investments and domestic demand. The recent slowdown in the region, recording an average rate of $1.4 \%$ in 2016 , reminds of the dependence of several countries on global market developments and the need to strengthen their resilience to external shocks as well as to reduce reliance on natural resources. Even fast-growing economies like Côte d'Ivoire, Ethiopia, Kenya, and Senegal have had important drawbacks in the medium and short runs in the form of growth breaks, budget deficits and large public debts, all of which question the sustainability of current trajectories (IMF 2017). In addition, unemployment is high, especially for the youth. This reflects among others the lack of productive opportunities, decent work as well as limited entrepreneurial and training opportunities (out of the informal sector) and fundamental mismatches between skills provision and market needs.

An overview of the inputs for innovation shows that the establishment of innovation policies in sub-Saharan Africa has come with increasing but still limited investments in R\&D $(0.41 \%$ of GDP in 2014$)$ as well as very low ratio of researchers per inhabitant (less than $90^{4}$ researchers per million inhabitants (FTE) in 2014, STI data UIS.stat). As a comparison, lower middle-income countries had 193 researchers per million inhabitants in 2013; in upper middleincome countries this figure was 888 . Yet, these aggregate figures hide major disparities between countries, substantial dependence on donor funding, shortage of high-quality infrastructures (transport, communications, universities, laboratories, S\&T centres) and a very low level of private sector funding, with the sole exception of South Africa (African Innovation Outlook 2010, 2014). Other related indicators suggest that sub-Saharan Africa is still lagging in terms of tertiary education institutions, intellectual property and innovativeness, productivity and competitiveness (UNECA 2016, ACBF 2017).

Apart from these structural shortcomings in terms of human capital and resources, policymaking in this region suffers from low administrative capacities to design and implement innovation policies with proper monitoring and evaluation mechanisms (M\&E). In existing national strategic plans for innovation these are often neither integrated nor specified (AOSTI 2014, AUC 2014). The lack of M\&E mechanisms renders it more difficult, if not impossible, to accurately assess STI budgets, implementation costs of policies as well as the relevance of impact studies. A key challenge in this respect is the recruitment of qualified analysts who can handle innovation data collection and analysis to inform the formulation and implementation of innovation policies.

Although different institutional and legal arrangements exist, the selection of investment priorities is often done in a top-down and centralized manner. Generally, prioritisation, if in place, does not rely on a thorough analysis of the local productive structure and assets that, ultimately, are supposed to materialize such priorities. Priorities at this level may be formulated in such a way that they can be related to any sub-activity of a given priority field (e.g. Agriculture, Health, Economy). The concern here is not so much about their formulation, but rather about how they can be translated into tangible industrial activities undertaken at the microeconomic level, which is well beyond the strategic documents writing. An important risk of such top-down strategies without evidence-informed prioritisation is that they disregard the specific local and socio-economic challenges and problems that innovation policy may address (World Bank 2010, UNCTAD 2017); this might also be described as "a-one-size-fits-all" approach to innovation policy-making, whilst we are aware that human capital, infrastructures and resources greatly differ across and within territories (e.g. countries, regions, cities and villages).

\footnotetext{
${ }^{4}$ This is equivalent to about 81,000 researchers (UNESCO, Unesco Institute for Statistics, UIS.stat). See also the overview on R\&I performance in Africa (Dosso et al, 2017).
} 
Another issue consists in the lack of local human resources for STI and the skills of the existing labour force when it comes to implement the STI priorities as well as to meet the market needs for scientists and engineers (S\&E). An estimation of the ACBF quantifies this shortage to about 4.3 million engineers and 1.6 million agricultural scientists and researchers, due mainly to excessive enrolment rate in social sciences and humanities (ACBF 2017). Urgent actions are needed to reverse these trends through the introduction of career and incentive mechanisms as well as better quality school teaching in mathematics and science to attract African youths towards S\&E education. Such interventions would benefit from collaboration with the private sector that should enhance its commitment to vocational and lifelong training of employees ${ }^{5}$. Empirical evidence strongly suggests that high quality education in science and mathematics is a critical factor determining economic growth (Hanushek and Wößmann 2010).

For many years, policy-making in STI has been focused on the S\&T component, overlooking the 'I' dimension of the policy (Iizuka et al 2015). This orientation has favoured a narrow perspective on innovation policies that are generally still perceived as linear interventions to improve the knowledge transfer from universities or research centres. Although such interventions are difficult to assess in the current informational context, they minimize the importance of non-R\&D-based and non-technological innovation as well as the benefits of enhanced interactions for innovation, both with the formal private sector and the civil society. The situation is even more unbalanced if we account for the weight of the informal sector in African countries and its hidden innovation potential (Kraemer-Mbula and Wunsch-Vincent 2016). In many traditional economies, it is the non-technological (especially process, organizational, marketing) innovation that answers better the needs of companies, including micro- and small entities that make most of economic fabric. The R\&D- based technological solutions are often non-affordable or the companies lack capacities to implement them, which changes only at the level of "big medium" or large companies, that often have their own R\&D staff. The focus on R\&D-based or "soft innovation" changes therefore the landscape of actors that will benefit from the policies that are put in place.

\section{Opportunities and challenges of a smart specialisation approach in the sub-Saharan African context}

Research and Innovation Strategies for Smart Specialisation (RIS3) are based on the concept of smart specialisation (S3, see Foray 2015) that describes how knowledge-based economic transformation agendas can be built. They aim at developing competitive advantages through matching research and innovation assets to local challenges and business sector needs and capabilities. To achieve this, policies must be evidence-based and tailored to the local context, acknowledging that different pathways for regional innovation and development exist. In the European Union (EU), the S3 approach has been promoted under the Cohesion policy ${ }^{6}$.

Figure 1 synthetises the main building blocks of a smart specialisation strategy: it starts from the constitution of an evidence base on the territorial potentials (S3 Evidence) in order to identify priority research and innovation domains (S3 Research \& Innovation priority domains). The S3 priorities should also be based on the specific needs of local companies and

\footnotetext{
${ }^{5}$ The recent declaration signed by the representative of the AU and more than 100 companies during the Africa Talks Jobs 2017 conference in Addis Ababa (Ethiopia) constitutes an exemplary step towards a greater and more concrete commitment of the private sector in the employability and training of youth on the continent.

${ }^{6}$ In the EU context, RIS3 were required as a legally binding ex-ante conditionality (regulation EU $1301 / 2013)$
} 
other stakeholders representing the priority domains. The S3 process is led and coordinated by a dedicated governance structure (S3 governance) which includes a high-level coordination team responsible for setting up the institutional framework for the design and implementation of S3, local or regional coordinating teams and dedicated entrepreneurial discovery groups.

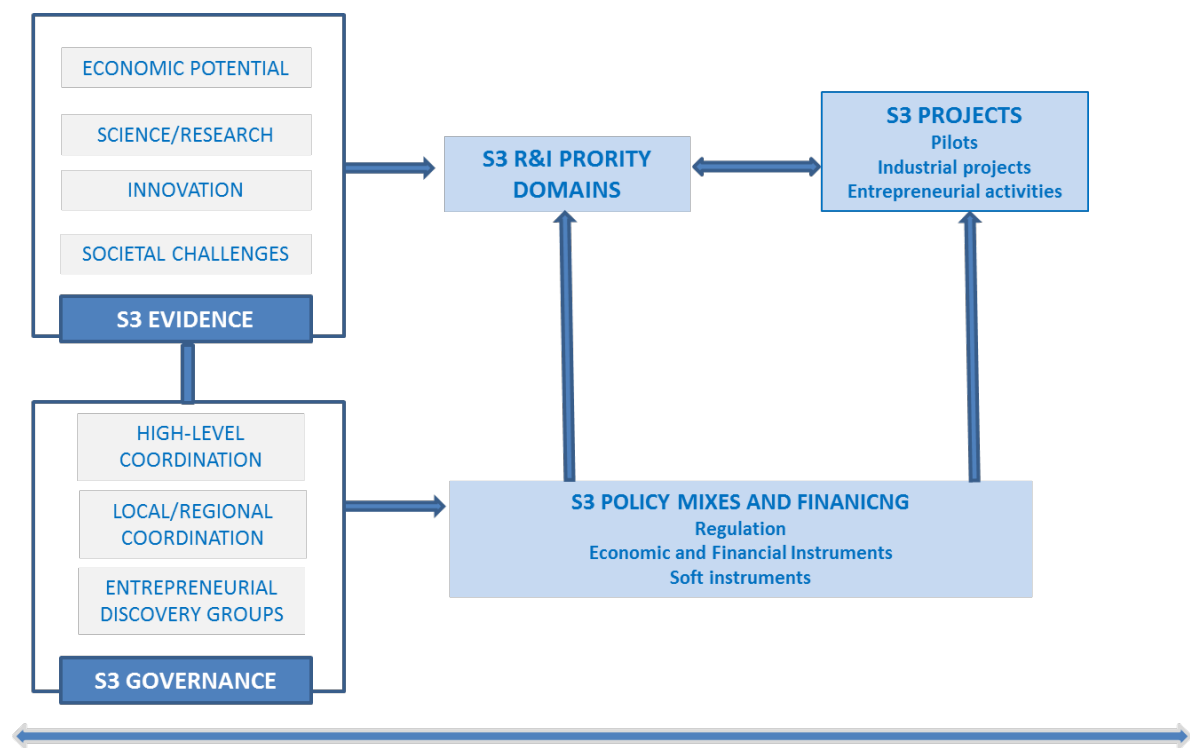

S3 Monitoring and Evaluation

Source: own elaborations

Figure 1. Smart Specialisation Strategy: overview of the main building blocks

Supported by S3 policy mixes and financing instruments ${ }^{7}$, the process ultimately leads to the selection or identification and implementation of investment projects in view of exploring or supporting future areas of competitive advantages for the territory. As for the overall strategy, the investment projects should be monitored and evaluated to ensure transparency and measurable impacts throughout the different phases of the process. The specific policy and financing instruments would depend, among other, on the countries' existing policy mix, the specific local challenges and needs related to priority domains and related projects.

Although various implementations mechanisms exist in Europe and the world ${ }^{8}$, the approach builds on a few basic principles ${ }^{9}$ :

(i) A critical mass of knowledge- and innovation-related investments (human resources, infrastructure, and funds) is needed to transform and adapt existing industrial structures;

(ii) Dedicated and monitored R\&D and innovation budgets should be oriented towards a few of priority activities or domains to build up sustainable competitive advantages.

(iii) These priority activities are identified through evidence-informed and participatory processes involving (ideally) actors from the quadruple helix in an entrepreneurial discovery

${ }^{7}$ The broad types of innovation policy instruments underlined here - Regulation, Economic transfers and Soft instruments - have been discussed more in depth by Borras and Edquist (2013).

${ }^{8}$ EU's Smart specialisation platform: http://s3platform.jrc.ec.europa.eu

S3 beyond EU: http://s3platform.jrc.ec.europa.eu/s3-beyond-eu;

S3 worldwide: http://s3platform.jrc.ec.europa.eu/s3-worldwide

${ }^{9}$ See Foray et al 2012 for the first official Guide on RIS3. 
process (cf. Box below). Such interactions also intend to limit ex-ante picking-the-winners or an exclusive support towards incumbent (large) firms. This also means that fundamental elements are trust and transparency in the selection and implementation of priority activities.

(iv) The strategies are place-based and oriented towards the mobilization, exploitation and promotion of local resources, entrepreneurs and interactions. At the same time, cross-sectorial activities should be stimulated and nurtured to favour the emergence of specific advantages (related diversification). This principle also implies that countries or regions should be able to map their current needs and assets (when possible with a SWOT analysis that builds on a comprehensive study of the economic, scientific and innovation potential of a given territory).

(v) Innovation in the S3 framework is not limited to technology creation, but encompasses also the adoption and diffusion of technologies and relevant knowledge as well as nontechnological innovations (e.g. organizational, social innovation). This broad view requires enlarging the policy scope beyond the exploitation of R\&D- and S\&T-related outcomes.

(vi) Thanks to the EDP, innovation is also business-led (not driven by science), allowing for easy applicability of new ideas and increases of their commercial value. Also, deeper understanding of business needs can stimulate more precise and more effective public support, as it is not given to all the possible beneficiaries, but a few carefully chosen cross-sectorial domains where the greatest value added and economic impact can be generated.

(vii) The strategy relies on tailored monitoring and evaluation mechanisms and a governance and management structure exhibiting unified leadership, while ensuring broad participation and ownership (for instance, through steering group, management team, etc.) for a continuous process. The results of monitoring and evaluation exercises allow for evidence-based updates needed to elastically adjust RIS3 to fast economic changes and needs of emerging sectors.

Box 1. Entrepreneurial discovery process (EDP): the distinguishing feature of smart specialisation

The EDP is an inclusive and participatory process for local decision-making, which brings together business, government, research and education institutions and civil society/consumer groups (users) to identify new domains for innovation and market opportunities. At the core of Smart Specialisation, EDPs ultimately lead to selecting and encouraging (existing or new) entrepreneurial activities that yield important potential for local development. EDPs go beyond the prioritization and requires the commitment of stakeholders during the implementation to ensure actors' trust and commitment to the objectives of the S3, and to align market needs and opportunities with policy interventions. EDPs should be designed according to the specific local context. An additional benefit is that by engaging key actors and encouraging them to take part in the process it influences behavioural changes in local innovation ecosystems. See http://s3platform.jrc.ec.europa.eu/entrepreneurial-discovery-process-focus-groups

Beyond these principles, a few practical lessons can already be drawn from this ongoing experience that Charles Sabel called "the biggest experiment in industrial and innovation policy" worldwide. Analysts point out the challenges and risks associated with the elaboration of such strategies (see for instance, Guimón 2013, World Bank 2015, Capello and Kroll 2016) and the need to think and design differentiated options and mechanisms according to a territory's development stage (World Bank 2010, Kleibrink et al 2017). Overall these works suggest that similar conceptual steps are necessary at the beginning of this process in order to use smart specialisation as an effective tool for development in developing countries and regions, and even more so in the specific sub-Saharan African socio-economic and cultural context. At least a few challenges are worth underlining: limited availability of official information and data on the productive structure and assets and the trust, commitment, leadership needed to sustain the strategy. While the latter factor relates more to medium term governance and cultural issues, the informational problem implies that RIS3 cannot be done (efficiently) without some consistent knowledge about the existing economic fabric. 
Nonetheless, as illustrated in Table 1, the smart specialisation approach can be linked to several aspects of current innovation policy (IP) at the local level in the sub-Saharan African context $^{10}$. The table compares the smart specialisation approach to the principles enshrined in the AU Strategy for STI, STISA-2024. The first column summarizes key implementation challenges of innovation policies in sub-Saharan Africa and the second column suggests how these latter ones may be potentially addressed in a smart specialisation framework.

Table 1. Mapping IP challenges and Smart Specialisation implementation principles.

\section{Challenges of IP implementation}

\section{Smart specialisation approach}

\begin{tabular}{ll}
\hline $\begin{array}{l}\text { Build institutional capacity for the design, } \\
\text { monitoring and implementation of STI policies and } \\
\text { international cooperation between AU Member } \\
\text { States }\end{array}$ & $\begin{array}{l}\text { Flexible, step-based \& gradual, S3 allows for policy } \\
\text { experimentation and learning }\end{array}$ \\
\hline $\begin{array}{l}\text { Make sure that the implementation plans match the } \\
\text { needs of varied and diversified territories of the } \\
\text { African states }\end{array}$ & $\begin{array}{l}\text { Place-based policy: valorise existing assets \& focus } \\
\text { implementation plans on local idiosyncrasies/needs }\end{array}$ \\
\hline $\begin{array}{l}\text { Generate commitment of local \& small } \\
\text { entrepreneurs and other actors for development }\end{array}$ & $\begin{array}{l}\text { Attention to and monitoring of local (micro-) } \\
\text { entrepreneurial dynamics } \\
\text { Including local actors in the decision-making process }\end{array}$ \\
\hline $\begin{array}{l}\text { An inclusive approach to knowledge- \& innovation- } \\
\text { based development }\end{array}$ & $\begin{array}{l}\text { Collective and inclusive governance and } \\
\text { experimentation (learning by doing \& by interacting) } \\
\text { Stakeholders from Quadruple Helix }\end{array}$ \\
\hline $\begin{array}{l}\text { Develop practical steps allowing for the successful } \\
\text { implementation of the strategy }\end{array}$ & $\begin{array}{l}\text { Include various actors (quadruple helix) in the } \\
\text { operational planning phase - they will help verify the } \\
\text { generated ideas (i.e. usefulness and applicability) }\end{array}$ \\
\hline
\end{tabular}

Source: own elaborations from STI Strategy for Africa, STISA (AUC, 2014) and Dosso (2017)

Human and organizational capacity-building for innovation policy development is required for evidence-based decisions (AUC 2014). Yet, the innovation systems in most SubSaharan Africa countries are often dominated by weak administrative capabilities and uncoordinated measures and actions (weak institutional links). The S3 framework promotes a step-based process where policy experimentation and learning take place, including across and within the public and the private spheres. Such approach may be relevant from the perspective of sub-Saharan Africa's innovation policymakers willing to set up STI governance structures, which enable a flexible and dynamic decision-making.

In the smart specialisation perspective, the focus is put on the assets and resources available to regions and countries and on their specific socio-economic challenges in order to identify unique opportunities for development and growth. Also in the sub-Saharan Africa, these calls for more local embeddedness in the formulation of policies and strategies are not new. However, it is still difficult to apprehend the extent to which current innovation policies (when they exist) include such bottom-up component.

\footnotetext{
${ }^{10}$ See also the background and synopsis of the debate on 'Territorial Innovation Policies and Smart Specialisation: a promising area for Africa-EU cooperation' organized by the European Commission's DG JRC at the European Development Days 2017, June, Brussels, The debate was organized with the official support of the AU's AOSTI and Côte d'Ivoire's institutions. See at https://www.eudevdays.eu/sessions/territorial-innovation-policy-promising-area-africa-eu-cooperation (latest access November 2017)
} 
While the entrepreneurial activity is peaking in many sub-Saharan Africa countries (Kelley et al 2015), entrepreneurs often face a lack of appropriate support both in terms of funding, infrastructure and entrepreneurial training, incubation and networking structures. When such concerns are combined with unclear rules of governing innovation activities and the absence of entrepreneurial activity monitoring, the socio-economic potential of local entrepreneurs is likely to remain underexplored.

As previously suggested, RIS3 take the form of collective and inclusive experimentations, where stakeholders from the quadruple helix commit and interact through an EDP to identify the domains of strong potential for development. This inclusiveness of the process intends to facilitate the realization of synergies and to limit the negative effects of vested interests and lobbying actions in the selection of industrial domains. Also in the AU's STISA (AUC 2014), inclusiveness is seen as a fundamental principle for the achievements of development goals. Yet, very few practical examples of such an approach exist in the sub-Saharan context.

\section{Concluding remarks}

In 2015, the Economist talked about Africa as the "pioneering continent" for technology policy with strong local potentials. Yet, these potentials remain largely untapped given the fragmented innovation systems and policy frameworks. The paper discusses how place-based economic transformation agendas could help African countries to develop competitive advantages through matching research and innovation assets to local challenges and business sector needs and capabilities. More comparative research is needed to better identify what works under given local conditions. Other critical cases like Rwanda, hailed by Minister of Youth and ICT Jean Philbert Nsengimana as "a startup country", should be studied to draw parallels and identify differences and conditions for effective innovation strategies.

Importantly, a first step of a Smart Specialisation Strategy is the assessment of the current strengths and challenges. Often combining quantitative and qualitative (expert) information, such territorial mapping constitutes a critical input for informed strategic policy decision, as for the identification of priority domains for economic transformation. A key implication is that potential pilot projects on smart specialisation in sub-Saharan Africa would require local S3 policymakers and stakeholders to constitute a sound and comprehensive basis of evidence. In this process, local and international (diaspora) expertise should be integrated both for benchmarking and for potential knowledge transfer and future collaborative exercises.

While the exact approach to smart specialisation in Sub-Saharan context has to be further studied and developed, the basic idea of involving local stakeholders (especially companies) in their own development through innovation is well matched with other, more generic development policies and can generate important synergies. In this context, and having in mind the size of the countries involved, a right institutional framework should be developed, where the national authorities provide the general directions and enable the development of the more specific, local and regional agendas where the appropriate public administration are also involved. The institutional framework needs to provide enough stability to generate and sustain motivation, commitment and trust of private sector.

A basic encouragement measure here can be to organize a few pilot actions that would lead to local "success stories" that are applicable and understandable for the local communities and build on the existing capabilities. The range of possible applications can vary from using the raw food products to create natural cosmetics (coffee waste is recently used by some EU companies to create organic body scrubs), analysing their medicinal and health properties and starting the development of functional foods, or promoting food design. All such exercises should lead to the identification of concrete examples of higher value-added products created by combining local resources and skills with knowledge and innovation. This will be a right base for bigger programmes in the future but can also generate natural spillover and synergetic effects even without the public sector intervention. 


\section{References}

AfDB, OECD and UNDP (2017), African Economic Outlook - Entrepreneurship \& industrialization. 316p.

ACBF, African Capacity Building Foundation (2017), Africa Capacity Report 2017, Building Capacity in STI for Africa's Transformation.

AUC, African Union Commission, (2014), AU Strategy for Science, Technology and Innovation for Africa 2024, STISA-2024, Addis Ababa: African Union.

AOSTI, African Observatory of STI (2014), STI Policy-making in Africa: An Assessment of Capacity Needs and Priorities, WP ${ }^{\circ} 2$, Malabo, Equatorial Guinea: AOSTI.

Borrás, S. and Edquist, C. (2013). The choice of IP instruments. TFSC, 80 (8), 1513-22.

Capello, R. and Kroll, H. (2016), From theory to practice in smart specialization strategy: emerging limits and possible future trajectories, EPS, 24(8), 1393-1406,

Dosso, M. et al (2017), Research \& Innovation, in European Commission, JRC, Science for the AU-EU Partnership: building knowledge for sustainable development, EU Publications.

Dosso, M. (2017), Smart specialisation in sub-Saharan Africa: opportunities and challenges An introductory note. European Commission, JRC, Seville, Spain (February 2017).

Fagerberg, J. (2006), Innovation. A guide to the literature, in J. Fagerberg, D.C. Mowery, R.R. Nelson (Eds.), The Oxford Handbook Of Innovation, OUP, Oxford, pp. 1-26.

Foray, D. et al (2012) Guide to Research and Innovation Strategies for Smart specialisation (RIS 3). European Commission, available at http://s3platform.jrc.ec.europa.eu

Foray, D. (2015), Smart Specialisation, Opportunities and Challenges for Regional Innovation Policy, Routledge, Abingdon (UK) and New York (NY)

Gianelle, C., Kyriakou, D., Cohen, C. and Przeor, M. (eds) (2016), Implementing Smart Specialisation: A Handbook, Brussels: EC, Luxembourg: Publication Office of the EU.

Guimón, J. (2013). Smart Decentralization of Innovation Policies, Policy Brief, World Bank, The Innovation Policy Platform: https:/www.innovationpolicyplatform.org (Nov.2017)

Hanushek, E.A. and Wößmann, L. (2010), Education \& Economic Growth, in: Peterson, P., et al (Eds.), International Encyclopedia of Education (3rd Edition). Elsevier, Oxford, 245-52.

Iizuka, M., Mawoko, P. and Gault, F. (2015), Innovation for Development in Southern \& Eastern Africa: Challenges for Promoting ST\&I Policy, UNU-MERIT Policy Brief, 1.

International Monetary Fund, (2017), Regional Economic Outlooks, Sub-Saharan Africa.

Kelley, D. et al (2015), The Global Entrepreneurship Monitor 2015/16, London, UK.

Kleibrink, A., Larédo, P. and Philipp, S. (2017), Promoting innovation in transition countries: A trajectory for smart specialisation, EUR 28638 EN, European Union.

Kraemer-Mbula, E., Wunsch-Vincent S. (2016) (eds.), The Informal Economy in Developing Nations - Hidden Engine of Innovation, Cambridge: Cambridge University Press.

UNCTAD (2017), New innovation approaches to support the implementation of the SDGs. United nations. http://unctad.org/en/pages/PublicationWebflyer.aspx?publicationid=1775

UNECA, United Nations Economic Commission for Africa (2016), Assessing Regional Integration in Africa (ARIA VII): Innovation, Competitiveness and Regional Integration, United Nations Economic Commission for Africa, Addis Ababa, Ethiopia.

UNESCO (2015), UNESCO Science Report: towards 2030, Paris, France, World Bank, (2010), Innovation Policy: A Guide for Developing Countries. Washington DC -, (2015), Smart Specialization in Croatia: Inputs from Trade, Innovation, and Productivity Analysis. Aprahamian, A., Correa, P. G. (eds). Directions in Development. World Bank. 